\title{
Use of the OSCOUR network data to describe low back pain attendances in French ED
}

\author{
Cécile Forgeot $^{1}$, Gilles Viudes $^{2}$, guilhem Noel $^{3}$, Anne Fouillet $^{1}$, Céline Caserio-Schönemann $^{1}$ \\ ${ }^{1}$ DATA, Sante publique France, Saint-maurice, France, ${ }^{2}$ Fedoru, Emergency regional observatory Federation, Paris, France, ${ }^{3}$ PACA Emergency \\ Network Observatory (ORUPACA), Marseille, France
}

\section{Objective}

The study describes the characteristics of attendances for low back pain (LBP) in the French emergency departments (ED) network Oscour ${ }^{\circledR}$, in order to give an overview of this disease before launching a prevention campaign.

\section{Introduction}

LBP is one of the leading contributors to disease burden worldwide [1]. In France, LBP is a frequent reason of general practice consultations. According to a study published in 2017 and based on 2014 data issued of the National Health Insurance CrossSchemes Information System (Sniiram) [2], this pathology stands for 30\% of thickness leave and 4 of 5 people will suffer of low back pain during their own life. Most often, LBP is a chronic pathology with acute episodes which most often require emergency care. In order to prevent chronicity, French health care insurance launched into a mainstream national prevention campaign during spring 2018. This campaign was also targeted for health professional to inform them of the best recommendations to provide to their patients. Then the French society of emergency medicine (SFMU) has been asked to relay this campaign to emergency departments (ED) where LBP is a frequent reason of attendance. Since 2004, the French syndromic surveillance system SurSaUD ${ }^{\circ}$ [3] coordinated by the French Public Health Agency (Santé publique France) daily collects morbidity data from the emergency departments (ED) network Oscour ${ }^{\circledR}$. Almost $92 \%$ of the French ED attendances were recorded by the system in 2017. The availability of this large ED dataset on the whole territory since several years gives the opportunity to describe LBP attendances before the potential fallout of the national prevention campaign.

\section{Methods}

For each ED attendance, the SurSaUD® system daily collects individual data containing demographic (age, gender, zip code), administrative (ED unit, date of attendance, transport...) and medical information (medical diagnosis (ICD10), chief complaint, severity, hospit.). These data are routinely analyzed to detect and follow-up various expected or unusual public health events all over the territory [3] and also constitute a large database to perform in-depth studies on specific public health issues. ED attendances with a medical diagnosis of LBP have been identified using at least one of the following ICD10 codes "M545", "M5450", "M5456", "M5457”, "M5458”, “M5459". Those data have been analyzed from 01/01/2014 to 31/12/2017 (504 ED) for the following age groups; less than 18 years old (yo), 18 to 34 yo, 35 to 49 yo, 50 to 64 yo, 65 to 84 yo and 85 yo and over, at national and regional levels. ED attendances have been also described by month, day of week and hour of day. Hospitalizations after discharge, stay duration in ED services, transport and associated diagnoses were also analyzed.

\section{Results}

From 2014 to 2017, 481,291 ED attendances for LBP were recorded corresponding to $1.12 \%$ of the total number of ED attendances with a coded diagnosis. $60 \%$ of annual ED attendances for LBP concern 18 to 50 years old adults. The proportion of LBP attendances among the all-cause activity remains stable between 2014 and 2017.

At the regional level, LBP proportion among the all-cause activity is similar to the national value in metropolitan regions $(0.8 \%$ in Brittany to $1.6 \%$ in Corsica) and is lower than the national value in overseas regions ( $0.4 \%$ in Mayotte to $0.8 \%$ in Guyane) except for Saint-Barthélémy $(1.8 \%)$.

At the national level, almost $10 \%$ of ED attendances for LBP are hospitalized after discharge. This proportion increases with age to reach $43 \%$ for the 85 years old and more. Proportion of hospitalization ranges between 5.6\% (in Paris area) and 17.1\% (in Brittany) in metropolitan regions and between 2.8\% (Guyane) and 9.3\% (Reunion island) in overseas regions. 
From 2014 to 2017, ED attendances for LBP remain stable by month. However, we observed a slight decrease along the week with more attendances on Monday (17.8\% of LBP attendances) than the other days. The attendances are more frequent in the morning (between 6 and $12 \mathrm{AM}$ ). At the national level, mean stay duration for LBP attendances in ED is almost 5 hours whereas median stay duration is 2 hours and 45 minutes. Stay duration is longer for patient arrived during night hours (from midnight to 6 AM) and for those hospitalized after discharge. Stay duration is also increasing with age. At the regional level, mean stay duration varies from 3 to more than 6 hours.

\section{Conclusions}

The broad coverage of the French ED network on the whole territory since several years enables to give an overview of ED attendances for acute LBP and their characteristics. One strength of the system is its strong partnership between epidemiologists and the ED physicians. It enables to verify that the results of the study are consistent with their perception on the field. The results of this study will be used as reference to evaluate potential benefits of this campaign. Finally, this study is a good illustration of how the syndromic surveillance system in collaboration with ED physicians, can quickly provide valuable data to support political strategies.

\section{References}

1. Maher C, Underwood M, Buchbinder R. 2017. Non-specific low back pain. Lancet. 389(10070), 736-47. doi:https://doi.org/10.1016/S0140-6736(16)30970-9. PubMed

2. Maladie A. Le patient adulte atteint de lombalgie commune; Livret d'information Octobre 2017 données SNIRAAM 2014, https://www.ameli.fr/sites/default/files/Documents/346618/document/lombalgieprofessionnels-de-sante_assurance-maladie.pdf

3. Caserio-Schönemann C, Bousquet V, Fouillet A, Henry V, pour l'équipe projet SurSaUD®. 2014. Le système de surveillance syndromique SurSaUD®. Bull Epidemiol Hebd (Paris). (3-4), 38-44. 